$$
\text { "Szekely" — 2009/6/7 — 16:51 — page } 139 \text { — \#1 }
$$

\title{
Teaching of problem-solving strategies in mathematics in secondary schools
}

\author{
ILDIKÓ SZÉKELY, KOZÁKNÉ
}

Abstract. In the Hungarian mathematics education there is no explicit teaching of problem-solving strategies. The best students can abstract the strategies from the solutions of concrete problems, but for the average students it is not enough. In our article we report about a developmental research. The topic of the research was the explicit teaching of two basic strategies (forward method, backward method). Based on our experiences we state that it is possible to increase the effectivity of students' problemsolving achievement by teaching the problem-solving strategies explicitly.

Key words and phrases: problem solving, problem solving strategies, developmental teaching experiment.

ZDM Subject Classification: D50, C30, E50.

\section{Introduction}

The Hungarian common national core curriculum designates the development of intellectual capacity of students and their personality as well as constructive thinking, teaching how to use the analogies as the fundamental task of school. It is accentuated as one of the educational goals of school that "it should give integrated, coherent view of mathematics not only as an accomplished, inflexible and austere system of knowledge, but also as particular human cognitive activity and mental conduct". ([10], p. 162) Skills, logical thinking, proficiency in solving mathematical problems, evolving a need for mathematical argumentation are among its general development requirements.

Unfortunately, in reality the above mentioned goals can be difficult to attain. I can also confirm this with my rich teaching experience. Most students can

Copyright (C) 2009 by University of Debrecen 


$$
\text { "Szekely" — 2009/6/7 — 16:51 — page } 140 \text { — \#2 }
$$

solve only standard tasks. When they face a new problem they are not able to use consciously and mobilize the learnt material (definitions, theorems, axioms, proofs) by themselves. Talented students are able to see the main points after some practicing, they do not only remember but also apply the main ideas. On the other hand, for average and weak students explicit emphasizing, understanding and acquisition of "reasoning operations would be very important" [4] Besides, in case of a lot of tasks the problem-solving strategy itself is, at least, as important as the result.

In spite of the fact that a lot of workbooks are published in Hungary every year, there are only few studies which actually teach students to solve the problems. And again, there are only few surveys which deal with this phenomenon. Mathematical problem collections contain chapters in which the students are supposed to be familiar with different problem-solving strategies, but it is the teacher's task to teach them these strategies. Unfortunately, course books are of no aid to teachers in their work. It is a good thing that in a Teachers' Treasury volume dealing with mathematics, practising teachers involved in such orientation can already find concrete help. [9] Problem-solving strategies can only be found in the book "Colourful Mathematics for the 6th class" in chapter "How to solve problems?", published by Mozaik Publishing House. There is a great need for updating the books by including not only the solutions of the problems but also the analysis of the applied solution strategies.

When speaking about problem-solving models we proudly quote György Pólya, but in teaching mathematics his principles are hardly put into practice.

In secondary school education mathematics as a science is in the centre. In the course of teaching the subject, the students' developmental level and difficulties in studying are left out of consideration. Laurinda Brown, a professor of Bristol University once remarked after her visit in Hungary: "You in Hungary teach mathematics, we in England teach children!" [3]

Hungarian training of outstanding ability students is of world standard, but less attention is paid to teaching of average students. How can we lend a helping hand to students not with the highest performance (10\%), but to those with average and respectively weaker results (90\%)? In my paper I examine this question.

Our results obtained in different surveys justify the necessity of changes in teaching practice, putting bigger emphasis on teaching problem-solving thinking. In series of the international PISA surveys, launched by OECD in 2003, on the basis of mathematical achievements Hungary took the $25^{\text {th }}$ place among 40 countries. As regards mathematics performance of the Hungarian students was below the
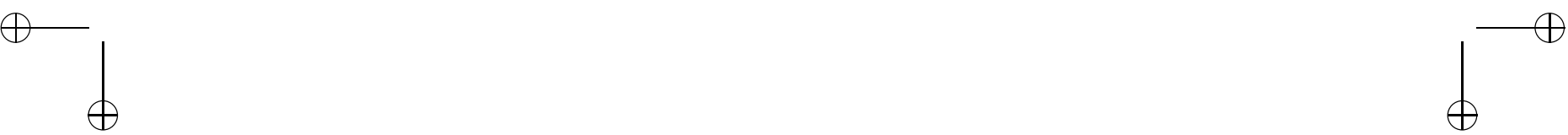


$$
\text { "Szekely" — 2009/6/7 — 16:51 — page } 141 \text { — \#3 }
$$

international average. The fact, that there haven't been any positive changes compared to the data obtained in 2000, the progress observed in the achievement of countries participating in OECD survey only deepened the difference between the well and poorly performing ones, gives food for thought. [11]

In order to investigate these problems I have carried out a developmental teaching experiment at József Attila Secondary Grammar School in Monor. The main questions of this experiment are: whether the problem-solving strategies could be taught, and to what extent explicit teaching of strategies enhances problem-solving skills of the students. In this study we focus our attention on two strategies: the forward method and the backward method.

\section{Developing teaching experiment}

\section{The main question of the experiment}

To what extent explicit teaching of problem-solving strategies (forward and backward methods) can contribute to the development of problem-solving skills of the average students?

\section{Hypothesis}

The problem-solving strategies can be taught and the explicit teaching of them increases the students' problem-solving skills significantly.

\section{Theoretical background}

\subsection{The concept of the problem in mathematics education}

According to the formal definition, 'problem' is an open question, or a task to be solved. [15]

A lot of researchers have dealt with the problem as a concept that appears in the process of teaching. In Bruders' formulation (1992) problems are such requirements of activity the students are confronted with, and for solving and fulfilling them they do not have any ideas or activity patterns at their disposal ([2], p. 107). According to Claus (1989) problems are such tasks in mathematical 


$$
\text { "Szekely" — 2009/6/7 — 16:51 — page } 142 \text { — \#4 }
$$

education to solve them one requires the combined application of several wellknown rules, and it is not obvious to the student.

Problem solving is a performance of intelligence as a typical human feature, which signifies resolute thinking and searching for means to achieve some set goals. ([12], p. 130) Experts involved in the research show great concern about the process, i.e. how moving towards the set goal takes place. The key issue of the problem-solving process is finding an appropriate solving idea. ([2], p. 122)

Another important factor in approach to the solution is the nature of the problem. This is a subjective category. What can be a problem for one student, can be a routine task for the other one. According to György Pólya a problem is 'big' if it is difficult and 'small' if it is easy to solve. ([12], p. 129) Anyway, there must be a certain level of difficulty to hallmark the problem; if there is no difficulty, and then there is no problem. If we can solve a task easily in no time without any hindrance, then it is just an evident thing to do I have reached my goal with. György Pólya speaks about two types of problems: 'defining problem' and 'proving problem'. The aim of a defining problem is to define something (to design, produce, obtain, identify...), the unknown element of a problem so that it fulfils the condition of matching the data to the unknown. The aim of a proving problem is to decide whether a statement is true or false, and to prove or contradict it. ([12], p. 131)

\subsection{Problem-solving in mathematics education}

\subsubsection{Heuristics; heuristic problem-solving strategies}

I use the concept of heuristics on the basis of György Pólya's given in his book 'How to solve it, A new aspect of mathematical method', in Hungarian: [13] Pólya quotes from Papposz when interpreting the concept 'So-called heuristics ... is a special field of science for those who, after thorough examination of general elements, are eager to gain the skill of solving of mathematical tasks.' ([13]. p. 200) In 'The Concise Dictionary of Heuristics' chapter we can find the following definition of the adjective 'heuristic': 'heuristic teaching or education encourages you to learn by discovering things for yourself'. Heuristic reasoning is a kind of reasoning which is not ultimate and strict, but just temporary and plausible; its aim is the solution of a set problem. In the chapter 'Modern Heuristics' ([13], p. 177) he writes the following: 'Modern heuristics ties to explore first of all those speculative elements, which are particularly useful in this process. Heuristics should be based upon experiences gained in the course of problem solving and 


$$
\text { "Szekely" — 2009/6/7 — 16:51 — page } 143 \text { — \#5 }
$$

problem solving observation. Meanwhile, we can't ignore any type of task solving and have to look for the signs that are common for various task solving processes. Our goal is tracing of such general characteristics, which are independent from the concrete subject of the problem.'

\subsubsection{Models of a problem-solving process}

György Pólya's problem-solving stages. [13].

- Understanding the task

- Planning

- Realization of our plan

- Analysis of the solution

Problem solving is a dynamic cyclic process: setting an objective, assertion of hypotheses, analysis of hypothetical consequences, rejection of hypotheses, assertion of a new hypothesis, etc. This characteristic is shown in the diagram below ([6]. p. 195-199)

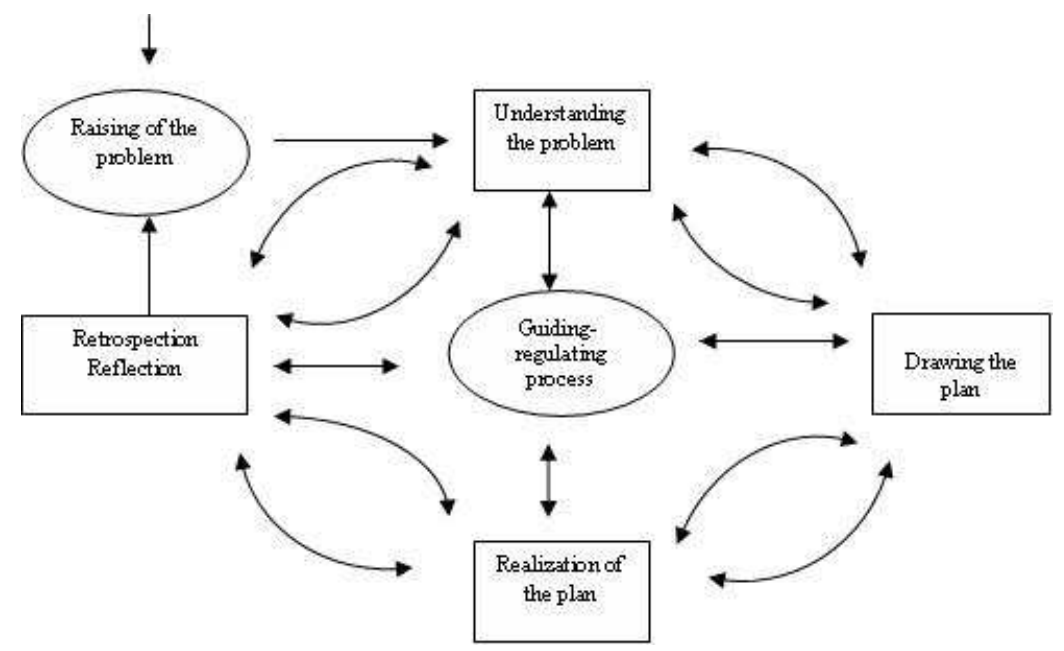

Figure 1

In scientific literature there is no unified conception concerning problem-solving strategies. Alfred S. Posamentier in his book 'Methods and Problem-Solving Strategies for Teachers' gives a detailed outline of ten strategies (1996) [14]. These is the following: 


$$
\text { "Szekely" — 2009/6/7 — 16:51 — page } 144 \text { — \#6 }
$$

1. Working backwards

2. Finding a Pattern

3. Adopting a Different Point of View

4. Solve a Simplier, Analogous Problem

5. Using Extreme Cases

6. Visual Representation

7. Intelligent Guessing and Testing

8. Accounting for All Possibilites

9. Organizing Data

10. Deductive Reasoning

In German scientific literature three basic strategies are emphasised:

- forward thinking / method

- backward thinking /method

- systematic trying

Other heuristic methods are called heuristic principles. They are the following: analogy; tracing a problem of non-evident origin back to the known one; principle of invariance; case differentiation; principle of optimality; examination of special cases; principle of symmetry; principle of transformation ([2], p. 118-122). In my study I shall deal with the first two strategies.

\subsubsection{Fundamental conditions of developing problem-solving skills}

According to Erich Ch. Wittmann these fundamental conditions are as follows ([16], p. 101-103):

1. Aquiring knowledge by "discovery" learning and teaching.

2. Urging students to use "diverse thinking" (using various wordings, approaching the same problem from different directions, connecting different fields of mathematics, mixing methods).

3. Pushing the exclusive application of automatical sequences of ideas into the background.

4. Examining open problems (there are no direct questions, there are different ways of putting up questions, and possibilities of research).

5. Urging students to raise questions and identify problems themselves.

6. Shaping a "language" that makes it possible for students to express their thoughts 


$$
\text { "Szekely" — 2009/6/7 — 16:51 — page } 145 \text { — \#7 }
$$

7. Urging intuitive reasonings and conjecture (a small but independent step is worth more than the picturing of a demonstrated chain of ideas).

8. Learning "heuristic" strategies.

9. Shaping a constructive attitude towards mistakes.

10. Urging discussions, reflections, and argumentations.

The ten above mentioned conditions are considered to be the basis of my pedagogical and research work. I tried to create and enforce the $6^{\text {th }}$ and $8^{\text {th }}$ conditions.

\subsection{Problem-solving strategies in secondary mathematical education}

\subsubsection{The forward method}

The main point of this proof strategy is the following: we start from the conditions of $A \Rightarrow B$ theorem, and such already known theorems, definitions and axioms from which we can get to a consequence through logically reasonable steps. If the consequence $\left(K_{1}\right)$ reached in this way is identical with the statement of the initial theorem, the proof is complete. If not, we will get to a consequence $K_{2}$ considering $K_{1}$ as the starting point. We will go on with this method until we get to a consequence $K_{n}$ which fulfils $K_{n}=B$. In case of a given problem $K_{i}$ s are interim steps. Our strategy can be symbolically drawn as the following:

$$
A \Rightarrow K_{1} \Rightarrow K_{2} \Rightarrow \cdots \Rightarrow K_{n}=B
$$

With different wording: $K_{1}$ is a necessary condition for $A, K_{2}$ is a necessary condition for $K_{1}, \ldots, B$ is a necessary condition for $K_{n-1}$. In the case of calculation and construction problems the goal object, data play the role of $B$.

Starting from the conditions we reach the goal through the chain of necessary conditions. The question that we must ask before every step during this proof strategy is: "What are the conditions of the theorem (problem)?", "What is the consequence of the given condition?", "What does it follows from the condition?" During problem solving the defined aim is always in the centre of thinking. [1]

This method has some difficulties: the initial step of proofs (problem solving tasks) seems to be too much sophisticated for the student. Many times they see the reason of why we start from this initial step only in the end. On the other hand when they succeed in finding this step, they have no difficulty in solving the problem, and the initial step will be reasonable for them. 


$$
\text { "Szekely" — 2009/6/7 — 16:51 — page } 146 \text { — \#8 }
$$

\subsubsection{The backward method}

Applying this method we start from statement $B$ of the $A \Rightarrow B$ theorem, resp. from the goal object, data. We try to find an $E_{1}$ sufficient condition to it. If we succeed and it derives from the conditions of the theorem (problem), already known theorems, deinitions and axioms, the proof is ready. If not, then we try to find other sufficient conditions in a similar way. If we succeed in finding an $E_{n}$ sufficient condition, which is a sufficient condition of $E_{n-1}$, and $E_{n}$ derives directly from the conditions of the theorem (problem), already known theorems, definitions and axioms, then we have proved the theorem, resp. solved the problem. The main point of the method is symbolically the following: $E_{1}$ is a sufficient condition of $B, E_{2}$ is a sufficient condition of $E_{1}, \ldots, E_{n}$ is a sufficient condition of $E_{n-1}$, and $A$ is a sufficient condition of $E_{n}$.

$$
B \Leftarrow E_{1} \Leftarrow E_{2} \Leftarrow \cdots \Leftarrow E_{n-1} \Leftarrow E_{n} \Leftarrow A
$$

Applying this method the questions are: "What does the theorem state?", "What is the goal object, data in the problem?" "Where does the statement derive from?" "How can we get the goal directly from other conditions, data?" [1] Formallogically this strategy is considered to be more difficult compared to the forward method, since it requires backward thinking. 'Backward' thinking can be followed with more difficulties for most of the students than forward thinking. Applying this method individual proof abilities and problemsolving skills improve much better.

\section{Circumstances and methods of the experiment}

\subsection{The experiment in brief}

The participants of the experiment were students of József Attila Secondary Grammar School, Monor. They are members of an extra curriculum maths class in the $11^{\text {th }}$ year. The students are from four different classes with different knowledge of mathematics, but with the intention to learn maths at a higher level during the following two years. As far as I know they are all from everyday families of Monor and its surrounding eight settlements with the intention of going on to higher education. After I had familiarized the students with the main question and hypothesis of the research, there were 20 students ready to take part in it, though this meant extra curricular work for them. Four students had mark three 


$$
\text { "Szekely" — 2009/6/7 — 16:51 — page } 147 \text { — \#9 }
$$

("Lower"), six had mark four ("Good") and ten had mark five ("Very good") from maths.

\subsection{Research methodology}

Applied research methods: monitoring the students, developing teaching experiment, pre-test, post-test, analysis of the written works of the students, talks with the students, surveying the students, reviews and disputes of the students' task-solvings.

\section{The process of the experiment}

\subsection{The pre-test}

During the survey 20 students got four tasks: two defining and two proving problems, and 45 minutes for solving them. They didn't get any instructions or help, but they could ask and sign when they could not go on. From the tasks determined in the pre-test the first and the second one were word problems, the third one was an algebraic proof, and the fourth one was a geometric proof. I chose the problems because the backward method offered a short and simple solution opposed to the forward method, and this way students who knew it, would apply this method. My goal with algebraic and geometric proofs was to get a picture about how the students approached these types of tasks, and how they could solve them without help. During writing the tests I encouraged the students to ask questions but they didn't grasp the opportunity.

Tasks of the pre-test

- A goldsmith sold half and 4 of his stock on Monday, on Tuesday he sold half and 2 of the rest, on Wednesday 5 pieces of jewellery, so he ran out of his stock. How many pieces of jewellery did he have on Monday morning?

- There are three players playing. The conditions of the game are:

a) two of them win and one looses after each round,

b) the loser is obliged to double the winners's money on hand.

How much money did they have when they started the game if after three rounds, from which all players lost one, they equally had 104 forints?

- Prove: if $a$ and $b$ are not negative numbers, then:

$$
\frac{a+b}{2} \geq \sqrt{a \cdot b} \text { ! }
$$




$$
\text { "Szekely" — 2009/6/7 — 16:51 — page } 148 \text { — \#10 }
$$

- Prove: if $P T$ is the tangent of a circle, $P B$ is the secant of this circle, and $A$ is the other point of intersection, then $P A \cdot P B=P T^{2}$ !

Table 1. Pre-test results

\begin{tabular}{|c|c|c|c|c|c|c|c|c|}
\hline & \multicolumn{3}{|c|}{ Forward thinking method } & \multicolumn{3}{c|}{ Backward thinking method } \\
\cline { 2 - 10 } Problem & $\begin{array}{c}\text { Number of } \\
\text { successful } \\
\text { solutions }\end{array}$ & $\%$ & $\begin{array}{c}\text { Number of } \\
\text { attempts }\end{array}$ & $\%$ & $\begin{array}{c}\text { Number of } \\
\text { successful } \\
\text { solutions }\end{array}$ & $\%$ & $\begin{array}{c}\text { Number of } \\
\text { attempts }\end{array}$ & $\%$ \\
\hline 1. & 7 & $\mathbf{3 5}$ & 9 & $\mathbf{4 5}$ & 1 & $\mathbf{5}$ & 6 & $\mathbf{3 0}$ \\
\hline 2. & 2 & $\mathbf{1 0}$ & 4 & $\mathbf{2 0}$ & 4 & $\mathbf{2 0}$ & 8 & $\mathbf{4 0}$ \\
\hline 3. & 0 & $\mathbf{0}$ & 3 & $\mathbf{1 5}$ & 0 & $\mathbf{0}$ & 9 & $\mathbf{4 5}$ \\
\hline 4. & 0 & $\mathbf{0}$ & 0 & $\mathbf{0}$ & 0 & $\mathbf{0}$ & 5 & $\mathbf{2 5}$ \\
\hline Total & $\mathbf{9}$ & & $\mathbf{1 6}$ & & $\mathbf{5}$ & & $\mathbf{2 8}$ & \\
\hline
\end{tabular}

While correcting the tasks of the pre-test I saw that in case of solving the defining problems (the first and the second tasks) more students $(80 \%)$ chose the forward method with success. I observed a big lack of knowledge in case of solving the proving problems, since there were no students to solve the third and fourth tasks successfully. Less than half $(45 \%)$ of the students preferred to apply the backward method when solving these tasks. Only $15 \%$ of the students tried both methods.

\subsection{The developing course}

I held the developing course five times after the lessons. (90 minutes each) At these lessons I followed the methodological thesis of Schoenfeld suggested in 'Problem Solving in the Mathematics Curriculum' (1983), and applied during the teaching practice. According to Schoenfeld the roles of the leading teacher are: demonstrative role, moderator and the teacher, the coach. The Demonstrative role means that during solving the problems together with the students the teacher demonstrates the possibilities, effectiveness, pitfalls of the use of different strategies, and the process of problem solving itself. As a moderator the teacher must use the students' proposals, react to their questions, and guide them with proposals, suitable questions. The coach role means that the teacher has to show, stress the simpliest way and method in case of problems accessible and solvable in more ways with '...try to do it in this way'. 


$$
\text { "Szekely" — 2009/6/7 — 16:51 — page } 149 \text { — \#11 }
$$

\subsection{1}

First I was talking about the types of the strategies, the different ways of thinking, the question which they have to ask from time to time when proving a theorem. (see II.3.3.1;3.3.2). I made the following board-draft:

\begin{tabular}{|c|c|}
\hline Forward method & Backward method \\
\hline Let's prove & the theorem: $A \Rightarrow B$ \\
\hline A: the condition of the theorem & Starting point: B statement of the theorem \\
\hline$B$ : the statement to be proved & To $B$ we are looking for an $E_{1}$ sufficient \\
\hline $\begin{array}{l}K_{1}: \text { the consequences of the } \\
\quad \text { interim steps }\end{array}$ & condition from which $B$ derives \\
\hline$A \Rightarrow K_{1} \Rightarrow K_{2} \Rightarrow \cdots \Rightarrow K_{n}=B$ & $B \Leftarrow E_{1} \Leftarrow E_{2} \Leftarrow \cdots \Leftarrow E_{n-1} \Leftarrow E_{n} \Leftarrow A$ \\
\hline Questions: & Questions: \\
\hline $\begin{array}{l}\text { What are the conditions of the } \\
\text { theorem? }\end{array}$ & $\overline{\text { What does }}$ the theorem state? \\
\hline $\begin{array}{l}\text { What derives from the condition? } \\
\text { What is our goal? }\end{array}$ & From what does the theorem derive? \\
\hline
\end{tabular}

Figure 2

I called their attention to the importance of wording and writing down their arguments, references to certain theorems, axioms, the data of the condition during problem solving every time. During this lesson we solved some tasks of the pre-test with the help of the discussed strategies. We elaborated the fourth task of the pre-test as the following:

Prove: if $P T$ is the tangent of a circle, $P B$ is the secant of this circle, and $A$ is the other point of intersection, then $P A \cdot P B=P T^{2}$ !

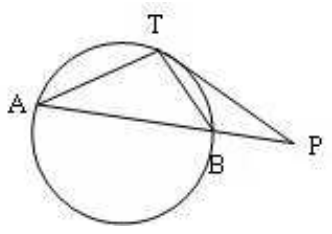

Applying forward method: During problem solving the defined aim is always in the centre of our thinking. What is the goal? What are the conditions of the theorem? What derives from the conditions? - we ask these questions. Our way of thinking is the following:

$K_{1}$ : Let's link points $A$ and $T$, and points $B$ and $T$ (draw the $T A$ and $T B$ segments).

$K_{2}$ : Let's examine $T A P$ and $T P B$ triangles! 
the angle at $P$ is in common

$T A P \angle=P T B \angle$ (they are perimeter angles on the same arc)

$K_{3}: T A P \Delta \sim T P B \Delta$ derives from the previous steps

$K_{4}$ : From this derives the equality of the corresponding sides, that is:

$$
\frac{B P}{T P}=\frac{T P}{P A} .
$$

$K_{5}$ : We reach the statement with applying the characteristic of the proportion. Applying backward method: The questions that we ask before all the steps applying this problem-solving strategy are the following: 'What does the theorem state?', 'Where does the given statement derive from?'.

The process of our thinking is the following:

$E_{1}$ : To show the statement to be proved, it is enough to prove the next equality:

$$
\frac{P T}{P A}=\frac{P B}{P T} \text {. }
$$

$E_{2}$ : To prove the equality of the proportion of the two segments, it is enough to find two similar triangles. With the segments we examine the $A P T$ and $P B T$ triangles.

$E_{3}$ : To prove the similarity of $P A T$ and $P B T$ triangles, it is enough to show the equality of two pairs of equivalent angles:

$A T P \angle=P B T \angle$ (they are perimeter angles on the same arc)

$T P A \angle=T P B \angle$ (they coincident).

The latter statements derive from the conditions of the theorem.

We have proved the original statement.

At the first task the use of the backward method was adventageous from more points of view. Firstly this problem-solving is much shorter. Secondly the danger of enumeration is much smaller. In the case of the forward method even writing the equation can be a problem. However, if they succeed, there is a big possibility of errors when calculating the compound fraction. In the case of the second problem, again, the backward method leads to the much shorter solution.

\section{2 .2}

During the second lesson we solved the following word problems:

- One of the co-operative farms divides its 1430 hectare cropland into three parts, because it is going to grow 3 different plants. If they reduced the area of the first part with $1 / 3$, the second part with $3 / 8$, the third part with $2 / 5$, they would get equal areas. How big are the three parts? 
- A card-player first loses the half of his money, than wins 50 forints. Then he loses $1 / 5$ of his remaining money, and wins 40 forints. After he loses $1 / 6$ of his reamining money and 50 forints more, this way he has 350 forints left. How much money did he have when he sat down to play?

- I have 200 forints in my two packets all together. If I put $1 / 4$ of my money and 20 forints more from one of the pockets into my other pocket, then I'll have the same amount of money in my two packets. How much money did I originally have in my two pockets?

- I have thought of a number. I substracted 5, then I divided this number with 3 , then I added 8, and divided this sum with 4 . The result is 3 . Which number did I think of?

Now again, I wrote the main points of the two methods on the board to refresh their memory, then they were given the first word problem. After a short thinking time I was curious about how my students started out. Half of them chose the strategy of the forward method and half of them the backward method. I put up helping questions for them, and made suggestions to solve the problem. In case of this problem the difficulty in case of the forward method is that a system of equations with three unknowns must be solved. As opposed, with the backward method there is only one unknown.

We discussed which strategy is more advantageous in case of all problems after solving them with both methods. Such kind of guidance can make the students parts of a problem-solving process, and the small pieces of success can be motivating in their future work.

\section{2 .3}

During the third lesson we did algebraic proofs. The problems were the following:

- Let us prove: if $a$ and $b$ are non-negative numbers, then:

$$
\frac{a+b}{2} \geq \sqrt{a \cdot b}
$$

- Let us prove the following inequality:

$$
a^{2}+b^{2}+c^{2} \geq a b+b c+c a ! \quad a, b, c \in \mathbb{R}
$$

- Let us prove: if $a$ and $b$ are positive numbers, then:

$$
\frac{a+b}{1+a+b}<\frac{a}{1+a}+\frac{b}{1+b} !
$$




$$
\text { "Szekely" — 2009/6/7 — 16:51 — page } 152 \text { — \#14 }
$$

- Let us prove the following inequality:

$$
a^{2}+b^{2}+c^{2}+\frac{3}{4} \geq a+b+c ! \quad a, b, c \in \mathbb{R}
$$

I chose problems where the application of the first- or the second strategy offered themselves. The first problem was one of the problems of the pre-test. This time I expected my students to be able to work independently. Most of them solved the problems with the backward method. After asking 'What does the task state?', Where does the given statement derive from?' questions with writing down sufficient conditions they could get to such a sufficient condition, which directly derives from the condition of the theorem. The difficulty of the forward method could be seen in case of these algebraic proofs. Finding the first steps was difficult. When I helped them to start with

$$
\begin{gathered}
(\sqrt{a}+\sqrt{b})^{2} \geq 0 ; \quad(a-b)^{2}+(b-c)^{2}+(c-a)^{2} \geq 0 ; \\
\frac{a}{1+a}>\frac{a}{1+a+b} ; \quad(2 a-1)^{2}+(2 b-1)^{2}+(2 c-1)^{2} \geq 0,
\end{gathered}
$$

then they had no difficulties in solving the problems. In case of algebraic proofs I called their attention to such steps which are usually forgotten in the problemsolving process. They are for example reconsideration of the solution, when does equality occure, or checking the solution.

\section{2 .4}

During the fourth lesson we made proofs in connection with triangles. Since collecting the sufficient conditions of the given geometric statements can be a great help for the students at both problem-solving strategies, I followed this during the first half of the lesson. We solved the following problems:

- The altitude of an acute-angled $A B C$ triangle starting from $A$ crosses $B C$ in $A_{1}$, the altitude strating from $B$ crosses $A C$ in $B_{1}$, the orthocenter is $M$. Prove: $A M \cdot M A_{1}=B M \cdot M B_{1}$ !

- The legs of a right triangle are $a$ and $b$. The part of the half-line dividing the right angle into three and closer to $a$ in the triangle is $h$. Prove:

$$
\frac{1}{b}+\frac{\sqrt{3}}{a}=\frac{2}{h} !
$$


- In a triangle opposite to $a, b, c$ sides the angles in order are $\alpha, \beta, \gamma$. Prove: if $\beta=50^{\circ}$ and $\gamma=100^{\circ}$, then $a \cdot b=c^{2}-b^{2}$ !

- Let us prove: if the bisector starting from vertex $A$ of the $A B C$ triangle crosses the opposite side in point $D$, then $\frac{1}{A B}+\frac{1}{A C}=\frac{2}{A D} \cos \alpha$, if $2 \alpha=$ $B A C \angle$ !

- Let us prove: the hypotenuse in any right triangle is at least as long as the sum of the legs multiplied with $\frac{1}{\sqrt{2}}$ !

Solving the first task most of the students noticed that transforming the products into proportions is enough to understand the equality of the fractions. They remembered that there are proportions in similar triangles. They chose the corresponding triangles and tried to prove their similarity. Some students could solve the task with the forward method successfully.

I also called their attention to another method, namely that we can think of the multiple of secant segments solving this task. We understand that $A B_{1} A_{1} B$ square is a circle-rectangle, and in the circle around, $A A_{1}$ and $B B_{1}$ are secants crossing point $M$. If we apply the secant-segments theorem here, we immediately reach the expression to be proved. Applying the train of thought of the backward method at this problem will give us a simple solution. All of its steps are simple. From the equality of the fractions the necessity of finding similar triangles is obvious after rearranging. After setting the problem the students had some time for thinking, and after a quick survey I could see that they only tried to use this method.

Using the forward method in the third task, after I had helped with the starting idea of "let's draw the bisector of angle $\gamma$ ", 5 students were able to go on with problem-solving. I also talked about the generalisation of the problem. It is the following: in a triangle opposite $a, b, c$ sides there are $\alpha, \beta, \gamma$ angles in order. Let's prove: if $2 \beta=\gamma$, then $a \cdot b=c^{2}-b^{2}$ !

\section{2 .5}

During the fifth lesson we made proofs in connection with triangles, rectangles, and trigonometry. They were the following:

- Let us prove: the angle bisector in the triangle divides the opposite side in the ratio of the two other sides! (the bisector theorem)

- In the trapezoid $A B C D$ the sum of the two angles on side $A B$ is $90^{\circ}$. The midpoint of $A B$ is $E$, the midpoint of $C D$ is $F$. Prove: $2 E F=A B-C D$ ! 
- Let us prove the following statement: if $x$ is a real number, and $\sin x=\cos x$, then $\operatorname{ctg} 2 x=0$ !

- Let us show that $\sin 40^{\circ}+\cos 40^{\circ}>1$ !

With the forward method in case of the second problem it is a good idea to draw the complementary triangle of the trapezoid. As we can see in Figure 3, after calling their attention, some of the sudents could go on with the proof by themselves. My other leading (helping) questions were as follows: If the sum of two angles on the base of a trapezoid is $90^{\circ}$, then what do we know about its complementary triangle? How long are the medians of the right triangle? Using the backward method they couldn't find enough sufficient conditions. I could only help them to the right solution with questions.

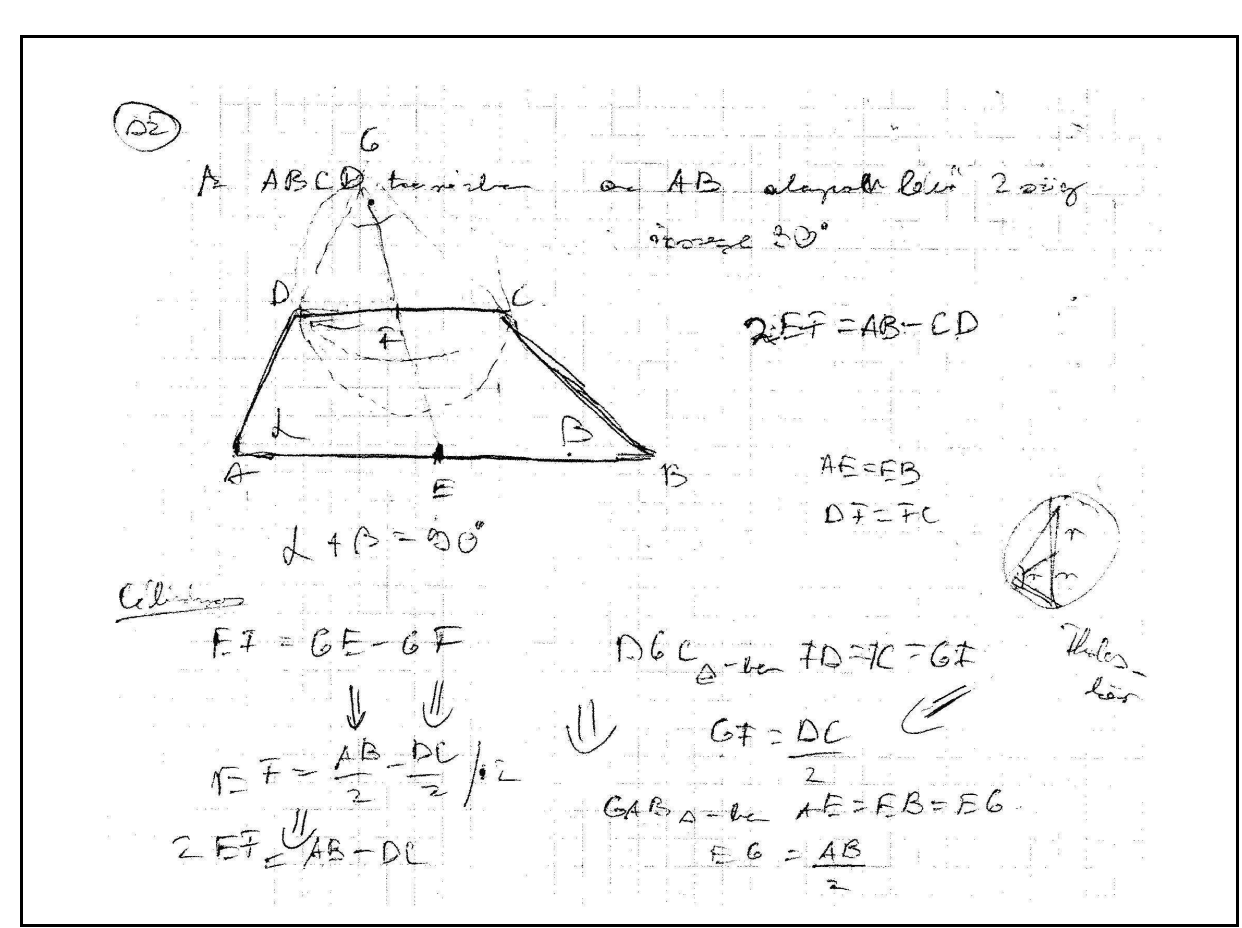

Figure 3 
In case of trigonometric proofs half of the students were able to solve the problem successfully with the backward method. With the forward method they were only able to solve the problem when I told them the starting idea.

\subsection{Post-test}

The problems of the post-test were the following:

- A mother divides a certain number of apples between her children as the following: Peter gets the half of the apples and two more, Pista gets the half of the remaining apples and two more, and Mari gets again the half of the remaining apples and two more. There is one more apple left. How many apples were there originally, and how many did each child get?

- The lenght of the legs of a right triangle are $a$ and $b$. The line-segment $d$ linking the vertex of the right angle and a point on the opposite side encloses angle $\delta$ with the leg $a$. Let us prove: $\frac{1}{d}=\frac{\cos \delta}{a}+\frac{\sin \delta}{b}$ !

- Let us prove: if $a, b, c$, are real numbers, then the following expression is valid:

$$
a^{2}+b^{2}+c^{2} \geq \frac{1}{3}(a+b+c)^{2} ! \quad \text { When can we find equality? }
$$

- The bisector starting from $A$ crosses the circle around the $A B C$ triangle in point $D$, and the $B C$ side in point $E$. Prove: $B D=\sqrt{A D \cdot E D}$ !

Table 2. Post-test results

\begin{tabular}{|c|c|c|c|c|c|c|c|c|}
\hline \multirow{2}{*}{ Problem } & \multicolumn{4}{|c|}{ Forward method } & \multicolumn{4}{c|}{ Backward method } \\
\cline { 2 - 10 } & $\begin{array}{c}\text { Number of } \\
\text { successful } \\
\text { solutions }\end{array}$ & $\%$ & $\begin{array}{c}\text { Number of } \\
\text { attempts }\end{array}$ & $\%$ & $\begin{array}{c}\text { Number of } \\
\text { successful } \\
\text { solutions }\end{array}$ & $\%$ & $\begin{array}{c}\text { Number of } \\
\text { attempts }\end{array}$ & $\%$ \\
\hline 1. & 7 & $\mathbf{3 5}$ & 5 & $\mathbf{2 5}$ & 4 & $\mathbf{2 0}$ & 12 & $\mathbf{6 0}$ \\
\hline 2. & 7 & $\mathbf{3 5}$ & 6 & $\mathbf{3 0}$ & 7 & $\mathbf{3 5}$ & 0 & $\mathbf{0}$ \\
\hline 3. & 3 & $\mathbf{1 5}$ & 4 & $\mathbf{2 0}$ & 7 & $\mathbf{3 5}$ & 12 & $\mathbf{6 0}$ \\
\hline 4. & 3 & $\mathbf{1 5}$ & 2 & $\mathbf{1 0}$ & 5 & $\mathbf{2 5}$ & 5 & $\mathbf{2 5}$ \\
\hline Total & $\mathbf{2 0}$ & & $\mathbf{1 7}$ & & $\mathbf{2 3}$ & & $\mathbf{2 9}$ & \\
\hline
\end{tabular}


$\bigoplus$

"Szekely" — 2009/6/7 - 16:51 — page 156 — \#18 ure 4):

Below we can see the problem-solvings of one students at the post-test (Fig-

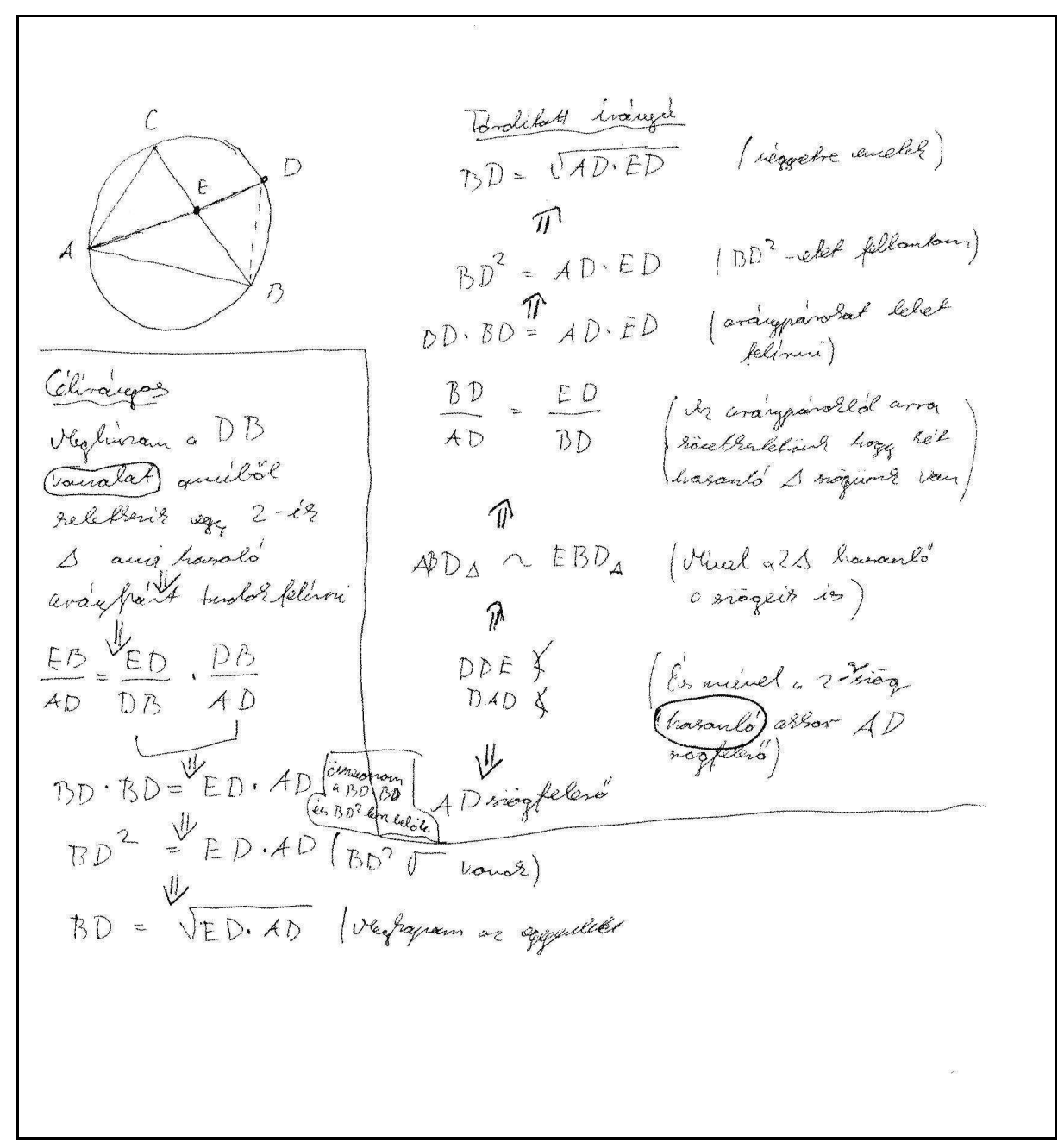

Figure 4 
The student applied both methods in a more or less successful way. The forward method: he linked points $D$ and $B$, then found similar triangles, and wrote the proportions of the corresponding sides. Through these interim steps he reached the statement to be proved. The backward method: the student could find sufficient conditions with a slight transformation of the statement to be proved (he brougth to a square, recognised that proportions can be written, they can be used in case of similar triangles, the sufficient condition of the similar triangles is offered by the $A D$ bisector).

\subsection{Evaluation of the results}

Comparing the results with the results of the pre-test my assumption has proved, that explicit teaching of heuristic strategies is necessary. If we describe the strategies to be applied in detail, the student will be able to use these strategies in the case of solving other problems. I had thought detailed explanation to be important, because next time, when they had to solve problems with similar strategies, the students were able to apply them consciously. Figure 5 and 6 are the works of the same student during the pre-test and the post-test. Both problems were of proof type, their solutions needed the same background knowledge and train of thinking. While during the pre-test (Figure 5) the student had no ideas, during the post-test (Figure 6) he could solve a similar problem with the backward method almost perfectly: as a sufficient condition he noticed that the angles belonging to the same circle are equal.

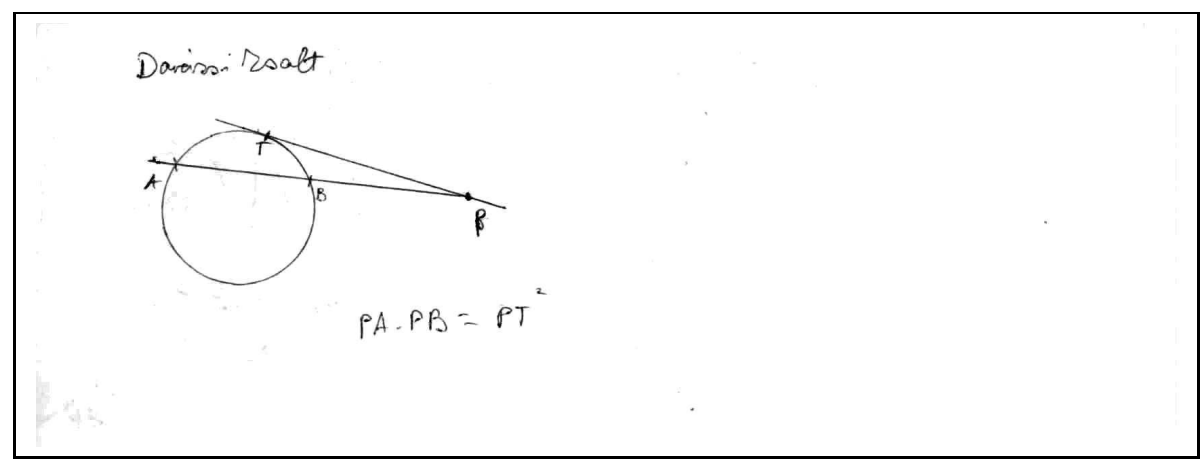

Figure 5

I also evaluated the work of the students with scoring. The maximum scores were $5-5$ for applying the forward- and the backward strategies in case of all 


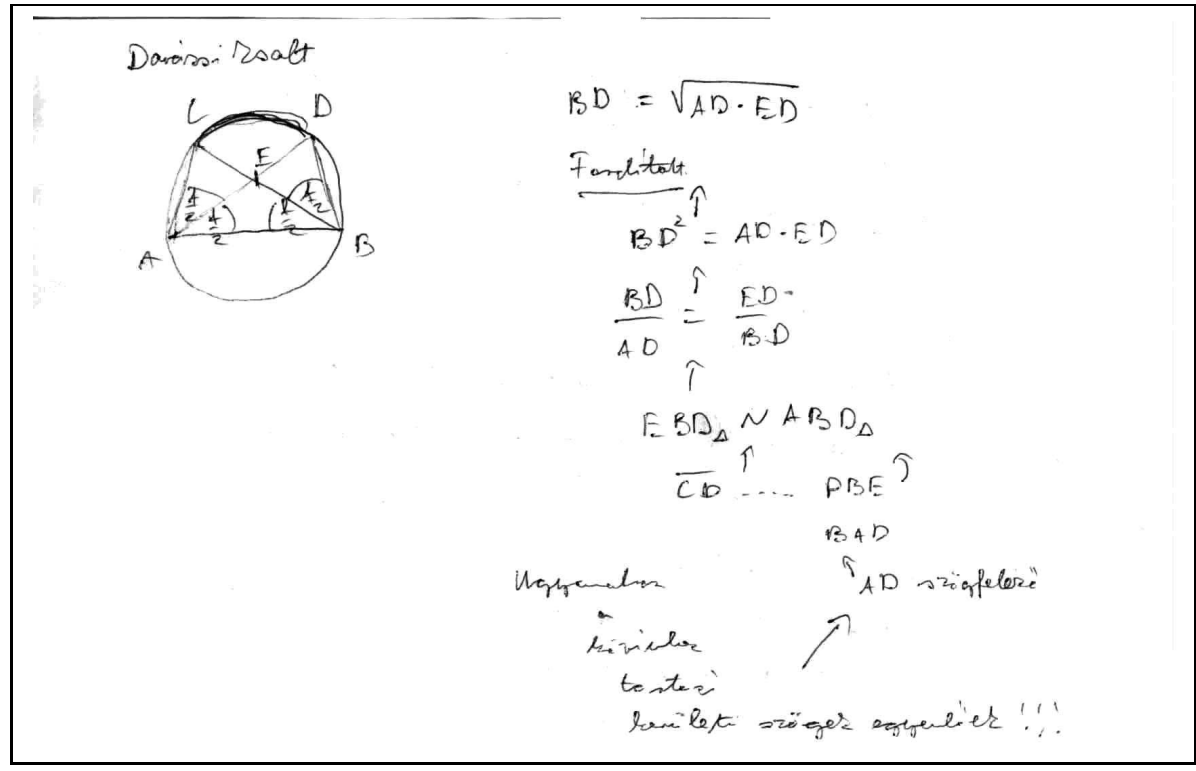

Figure 6

Table 3. Results of the pre-test and the post-test

\begin{tabular}{|c|c|c|c|c|c|}
\hline \multirow[b]{2}{*}{ Problem } & \multicolumn{2}{|c|}{ Forward method } & \multicolumn{2}{|c|}{ Backward method } & \multirow{2}{*}{$\begin{array}{l}\text { Number of } \\
\text { students who } \\
\text { tried both } \\
\text { methods }\end{array}$} \\
\hline & $\begin{array}{l}\text { Number of } \\
\text { successful } \\
\text { solutions }\end{array}$ & $\begin{array}{l}\text { Number of } \\
\text { attemps }\end{array}$ & $\begin{array}{l}\text { Number of } \\
\text { successful } \\
\text { solutions }\end{array}$ & $\begin{array}{l}\text { Number of } \\
\text { attemps }\end{array}$ & \\
\hline Pre-test & 9 & 16 & 5 & 28 & 3 \\
\hline Post-test & 20 & 17 & 23 & 29 & 12 \\
\hline $\begin{array}{l}\text { Increase of } \\
\text { performance } \%\end{array}$ & 112 & 6,25 & 360 & 3,57 & 300 \\
\hline
\end{tabular}

problems. I gave 4 scores for those who didn't examine the equality, or didn't refer to equivalent transformations, or the reasoning was imperfect in the case of the triangles during solving the problems. Those students who wrote for example a good equation but the calculation was bad, or recognised that they had to look for similar triangles but didn't finish the proof, or didn't give the reason for the similar triangles, were given 3 scores. 2 scores were given when they could write the data broken down to days or children, but did not finish, or transformed the product into a proportion, or wrote the $\geq$ relation with square sums, but made more mistakes or stopped calculation. I gave 1 score for making a correct 


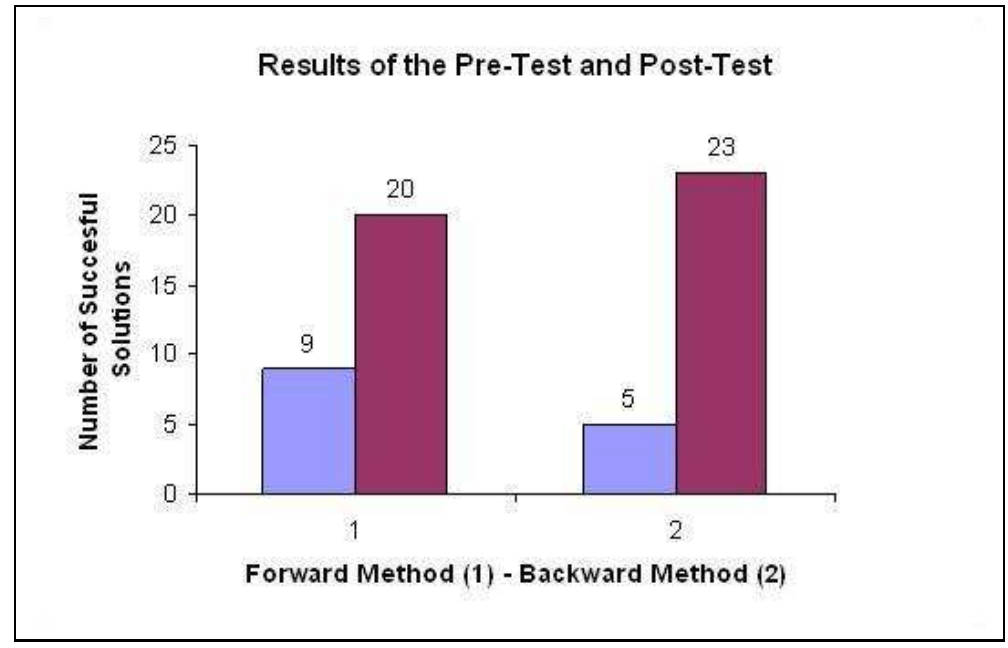

Figure 7

diagram, or tried to put the data in a table, but made basic mistakes in case of the fractions with the operations. I gave 0 score for unusable diagrams, the process of thinking was inadequate, or for the lack of ideas in connection with the problem.

Table 4. Results in points

\begin{tabular}{|c|c|c|c|}
\hline Problem & Pre-test & Post-test & $\begin{array}{c}\text { Increase of } \\
\text { performance }\end{array}$ \\
\hline Problem 1. & 79 & 113 & $43,04 \%$ \\
\hline Problem 2. & 61 & 93 & $52,46 \%$ \\
\hline Problem 3. & 39 & 103 & $164,10 \%$ \\
\hline Problem 4. & 13 & 58 & $346,15 \%$ \\
\hline
\end{tabular}

Based on the significance calculations [5] we can assume with $99 \%$ probability that the result is significant. The differences between the mean values of the preand post-tests is not by chance, but the result of programmed teaching (developing course).

Conclusion: During the survey, explicit teaching of the two problem-solving methods applied in the developing lessons was successful for the participating students. 


$$
\text { "Szekely" — 2009/6/7 — 16:51 — page } 160 \text { — \#22 }
$$

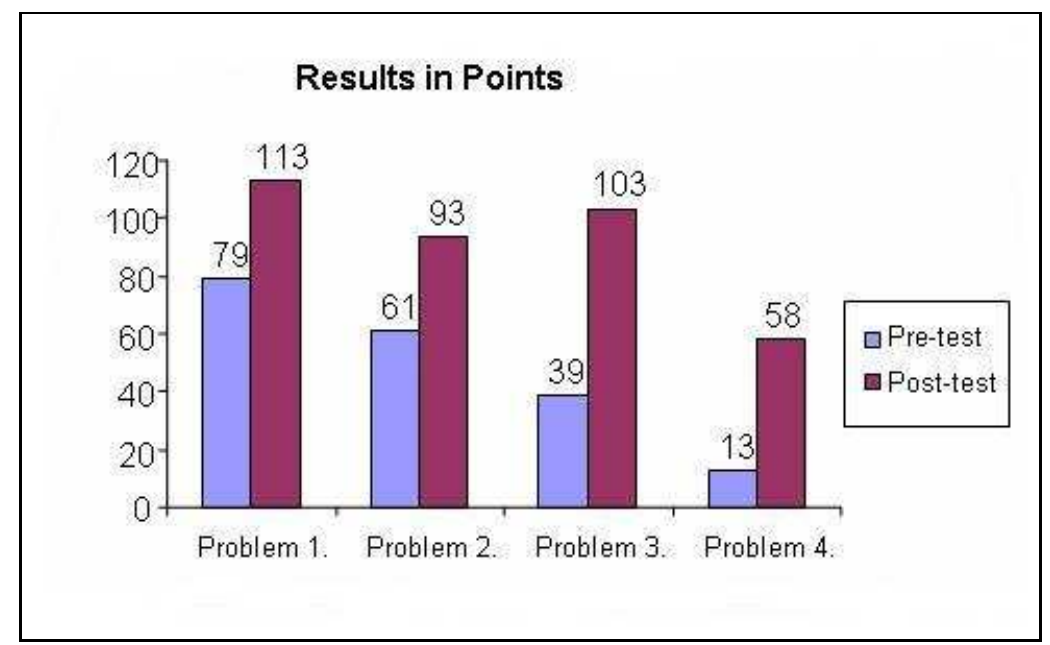

Figure 8

\subsection{A questionnaire for the students}

During my research and developing teaching experiment I considered important to get to know the attitudes of the students, in harmony with Schoenfeld's statements. For this reason the students answered a questionnaire complied by myself after the post-test. In this I asked the students to tell their opinions about the developing courses and the strategies they had got to know. Which problems they liked, which one was informative, what concrete difficulties they met after raising problems, what problem-solving strategies fitted them better, and in which they were still uncertain. I asked them to evaluate their work, change of their performance after the developing lesson.

From the answers to the survey I got to know that they were more satisfied with their performances after the developing course, they had usable ideas to solve the problems, they started proofs either with the forward- or the backward method with more courage. Now I quote some students' answers:

G. H. - his half-term maths mark: 4

'For me those problems seemed to be easier and solvable, where I could calculate with the backward method... I improved the most in solving the geometric tasks. I improved a lot thanks to the lessons.'

G. T. - his half-term maths mark: 4

'I think that these tests helped me a lot in developing my logical thinking. I got to 
know that the problems must be examined from more points of view to solve them in a quicker and successful way ... I liked the proof problems the best. I think they were the most useful.'

A. D. - his half-term maths mark: 5

'I think these tests were very good, because I could improve a lot during this time. I learnt to solve the tasks with differet methods. I improved a lot in solving proof tasks.'

L.A.- her half-term maths mark: 4

'During the pre-test I couldn't solve those types of problems. I think forward thinking fits me better. When we wrote the post-test, there were already problems which I could solve with the backward method.'

G. J. - his half-term maths mark: 5

'During the developing course I had the opportunity to get to know the forwardand the backward thinking. It was very useful for me because using the two, or at least one method I can solve any problem. ... All in all I'm happy with taking part in the programme.'

M. B. - his half-term maths mark: 5

'I was happy to take part in this developing programme. The main point was to learn how to govern thinking .... If there were another programmes like this one, I would enroll for sure.'

\section{Evaluation of the results. Conclusions}

1. After comparing the surveys before and after the developing cours it turned out that the number of successful solutions has grown: it was $112 \%$ in case of the forward method and $360 \%$ in case of the backward method. These data unambigously show that the developing course was useful for the sake of successful problem-solving.

2. There was also improvement in case of the approach of problem-solving. The number of those who tried to apply both strategies was growing; while there were only 3 students, $15 \%$ of the total number, who tried both methods with more or less success, after the developing course there were 12 students, $60 \%$ of the total number, who applied both methods. Four of them, $20 \%$ of the total number, worked successfully or almost successfully in case of two tasks. (Table 3.) 
3. Comparing the results of the two surveys we can see the differences in the case of the proof problems. At the survey after the developing course their performance was almost twice as good as at the test before the course (Table 4). In case of the successful backward method we can see that their improvement is also significant, 4.6 times better (Table 3 ).

4. It is an informative experience that they can't apply the two methods in the same degree. The number of successful solutions grew in case of both strategies, but not in the same degree: three times more students used the backward method than the forward method successfully.

5. It was a typical deficiency that more students solving a problem finished at calculating a value, or in a given situation at a wanted expression. They did not feel the necessity to evaluate the result or to examine the special cases. For example: when is a formula only positive and when does equality occur.

6. As a result of the developing course after the post-test, half of the students could tell that after reaching a formula or true statement through a chain of sufficient conditions, the original statement was true. This can be observed in case of one of the students' work in the post-test, where the backward method was used consciously. (Figure 5,6.)

7. From the post-tests it can be seen that the students' working processes have changed. They are able to consciously select a strategy or in case of failure they can change strategies. We know this also from their answers to the survey. As a result of this developing course both the knowledge and the thinking flexibility of the students have improved.

8. From the answeres given to the questions of the survey it turned out that after the developing course they had more ideas to solve the problems, so they were more satisfied with their own performances after writing the post-test.

9. Another important observation: a positive attitude can be later seen in case of solving such problems.

\section{Conclusions:}

1. It can be a significant help for the students in developing their problem solving skills if we organise the theorems according to their conditions and statements.

2. We call the attention that the logic sources of a theorem can be different, furthermore, different logic premises can have the same consequences.

3. In case of the backward proof methods it can be a big help for the students if we collect the sufficient conditions of geometric statements. 
4. It is important to teach both strategies to the students, so that they can achieve successful solutions the most effectively in case of a given problem.

PISA test - an international student assessment programme (Programme for International Student Assessment). It is a series of surveys initiated by the OECD (Organisation for Economic Cooperation and Development) to assess 15-16-yearold students how they are able to utilize their knowledge, how much new knowledge they are able to receive and use. The test is repeated every third year. In 2000 reading-comprehesion was in the focus in 32 states, in 2003 it was already 40 states where Mathematics was assessed, and in 2006 natural sciences got an outstanding attention.

\section{References}

[1] A. Ambrus and G. David, Proof Strategies of Teaching Mathematics in Schools, Mathematics Teaching V, 1984 (in Hungarian).

[2] A. Ambrus, Introduction to mathematics-didactics, University notes, ELTE Eötvös Kiadó, 1995 (in Hungarian).

[3] A. Ambrus, The need of concrete and visual presentations in teaching mathematics in schools (in Hungarian),

http://xml.inf.elte.hu/ mathdid/ambrus/aarepr.pdf.

[4] A. Ambrus, Theoretic bases of problem-solving teaching, 2002 (in Hungarian), www. oki.hu.

[5] I. Falus and J. Ollé, Statistical methods for teachers, Okker Press, 2003 (in Hungarian).

[6] M. L. Fernandez, N. Hadaway and J. W. Wilson, Problem Solving, Managing It All. The Mathematics Teacher 87 (3), 1994.

[7] I. Hortobágyi, P. Marosvári, L. Pálmai, A. Sipos and Ö. Vancsó, A comprehensive collection of mathematical problems for the school leaving exam I-II, Konsept- $H$ (2003) (in Hungarian).

[8] J. Kosztolányi, Developing problem-solving skills, Mathematics - Teachers' Gold-mine, September, 2007 A 2.11-6 (in Hungarian).

[9] Mathematics - Teachers' Gold-mine, Raabe Consulting and Press Ltd., Budapest, September, 2007 (in Hungarian).

[10] Ministry of Education, National Curriculum 2003, Budapest, 2004 (in Hungarian).

[11] PISA - test, www.om.hu.

[12] Gy. Pólya, Problem-Solving in School Mathematics I., Tankönyvkiadó, Budapest, 1970 (in Hungarian).

[13] Gy. Pólya, How to solve it, A new aspect of mathematical method (School of thinking), Gondolat Press, Budapest, 1977 (in Hungarian). 
[14] A. S. Posamentier and Steohen Ktulik, Teachers! Prepare Your Students for the Mathematics for SAT*I. Methods and Problem_Solving Strategies, Corwin Press, 1966.

[15] Facsimile publishing of Révai KIS LEXIKON, Révai, Budapest, 1936, ÉSZ_ÉRV Bt., 1994 (in Hungarian).

[16] E. Ch. Wittmann, Grundfragen des Mathematicsunterrichts, (6th ed.), Braunschweig: Vieweg, 1981.

ILDIKÓ SZÉKELY, KOZÁKNÉ

JÓZSEF ATTILA SECONDARY GRAMMAR

AND VOCATIONAL SCHOOL

ADY ENDRE U. $12-14$

2200 MONOR

HUNGARY

E-mail: kiszekely@yahoo.com

(Received July, 2008) 